\title{
INTER-RELATION OF PSYCHOLOGICAL SAFETY, COURAGE AND VULNERNABILITY IN THE WORKPLACE
}

\author{
Dr. Jayashree Sapra \\ Amity School of Business \\ Amity University, Noida, India
}

\begin{abstract}
This paper integrates the theories and findings of three emerging concepts psychological safety, courage, and vulnerability and their inter relation in the workplace and organization, topically and applications, is of major importance for leaders, HR professionals, engineering, IT companies and change agents. Psychological safety refers to the situation wherein one can express their views without the fear of getting judged, Courage refers to the way one responds to their fears and overcome them, lastly, Vulnerability is the willingness to expose oneself to a threat or uncertainty. All these three concepts are related to one another. Each of these concepts contributes to the existence of the other. A working definition of these concepts are provided in this paper along with an empirical research that has focused on understanding the essence of psychological safety, courage, and vulnerability, contributing factors, and exploring its consequences for individuals, teams, and organizations. The ways through which these are implemented or can be implemented in the organization are also included in this paper. The concluding part gives a speculative discussion for future policy makers. This paper highlights a conceptual framework which is based on theory and is used to highlight the relationship between the said factors in the workplace and further to understand the implications of these factors in an organization.
\end{abstract}

Keywords: psychological safety, courage, vulnerability, workplace, organization

\section{INTRODUCTION}

The purpose of this paper is to highlight the relationship between the three emerging terms of psychological safety, courage and vulnerability at workplace. The corporate world has now started to recognize the importance of the people associated in their organization, relating to which there are certain factors which when incorporated in the behaviour of the employees can lead to a situation of growth for both the organization and the employees.

This report investigates the psychological factors of human behaviour that can lead to a significant difference in their approach towards work and suggest for the implications of such factors by the leaders.

\author{
Bhavya Kumar \\ Amity School of Business \\ Amity University, Noida, India
}

First explored by pioneering organizational scholars in the 1960s, psychological safety experienced a renaissance starting in the 1990s and continuing to the present. Organizational research has identified psychological safety as a critical factor in understanding phenomena such as voice, teamwork, team learning, and organizational learning, Edmondson, A. C., \& Lei, Z. (2014).Although several concepts of psychological safety have been suggested, most studies followed Edmondson (1999) by describing it as a common belief among individuals as to whether participating in interpersonal workplace risk-taking is safe (Edmondson, Dillon, \&Roloff, 2007; Edmondson \& Lei, 2014). In a psychologically secure work atmosphere, workers believe that their colleagues do not condemn people for being themselves or doing what they think, respect the integrity of each other, are interested in each other as individuals, have good intentions with each other, are able to participate in productive conflict or disagreement and believe free to experiment and take risks.

\subsection{Psychological Safety}

Psychological safety is referred to being able to present your opinions without the fear of being judged or facing the negative consequences from the people around you. (Amy Edmondson, 2004). It further helps in the process of idea generation. The presence of psychological safety in a work environment helps the people to overcome anxiety or the defence mechanism that is evoked at the time of being informed about their shortcomings. (Schein, 1985) It gives us a platform to admit our mistakes, learn from failures, sharing of ideas and better decision making. It leads to an environment where employees are encouraged to share their views.

Psychological Safety can be highlighted at individual, team and organizational level. At the individual level it mainly deals with the feeling of a person where they feel free from anxiety and fear and are well verse with their needs. At the team level, psychological safety is the trust between the team members and the similar beliefs and values which are the underlying principles of the team. Psychological safety at organizational level is related to the environment at workplace which reflect trust and openness in the organization. (Ming Chen, Xiaoying Gao, Huizhen Zheng and Bin Ran, 2015)

Psychological Safety can be inculcated in a working environment through supporting the employees, clear role allocation, continuous learning, valuing ideas, providing due credit, enhancing human relations etc. The presence of this 


\section{International Journal of Engineering Applied Sciences and Technology, 2020 Vol. 5, Issue 3, ISSN No. 2455-2143, Pages 562-567 \\ Published Online July 2020 in IJEAST (http://www.ijeast.com)}

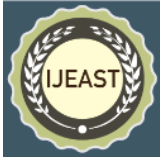

concept within the organization can possibly lead to the growth of the individual and the organization. It provides a basis for the concept of vulnerability within the organization. The consideration given to the aspect of psychological safety will give the people a sense of security to express their views without harming their image, status or career. It is a situation where the employees are comfortable enough to be a part of the organization and through the presence of a sense of belongingness.

\subsection{Courage}

Courage is the first human behaviour that guides all other human behaviours (Aristotle- Nicomachean Ethics, 1980). He denotes courage with the presence of fear and the power to overcome those fears. It is referred to our response to the fear when we are in such a situation. Being courageous is not the absence of fears but the acknowledgement of those fears. According to Simon Sinek (2014), when we trust our surrounding in case of our own safety we tend to be courageous in presenting what we actually believe in which helps us to take a risk and try out something new. Vulnerability, trust, skills and clarity of values act as the pillars of courage.

Courage tends to allow people to speak up and voice their opinions, brings out the creativity of the members of the organization, acts as a guiding force towards entrepreneurial decisions and also leads to an ethical decision making. It is related to be of dispositional nature. (Pauline Shilpzand, 2008) The courage quotient is the capacity of a person to manage their fears (Dr. Robert Biswas Diener, 2013). Courage is further attributed to taking the first step in a situation where we are not sure of the outcome. The attribute of courage helps us to believe in ourselves, our values and the abilities of self. It is the path or the willingness a person reflects to confront anger, fear and uncertainty. It enables one to take risks. Risks does not denote to a negative aspect necessarily but the uncertainty of the implications of such an action.

\subsection{Vulnerability}

Vulnerability has most often been denoted to be a negative aspect and not something that could lead to growth but Vulnerability has been identified as one of the most important tool in an emotionally intelligent leader's toolkit. (Brené Brown, 2010) She has defined vulnerability through the use of the words "risk, emotional exposure and uncertainty" and the birthplace of authenticity, accountability, hope, empathy.

Vulnerability highlights the presence of individual differences and the fact that something might be an act of vulnerability for one but not for another. The relation between psychological safety and vulnerability intersect in this domain where in order to put forward one's individual differences and the weaknesses or the inabilities they require an environment of trust and safety, an environment which is not judgemental which is related to the concept of psychological safety. Vulnerability is expressed in situations of asking for help, admitting fears, being accountable. The feeling of vulnerability is something where a person feels that they are uncovering the things that they had stored within themselves and removing their masks to put out their real selves. When a person realises the importance of vulnerabilities and puts out their feelings they reach at the situation where they do not have to spend their time pretending to be someone or knowing everything. Vulnerability can be measured through the courage to be imperfect, compassion and connections. (Dr. Brené Brown, 2010)

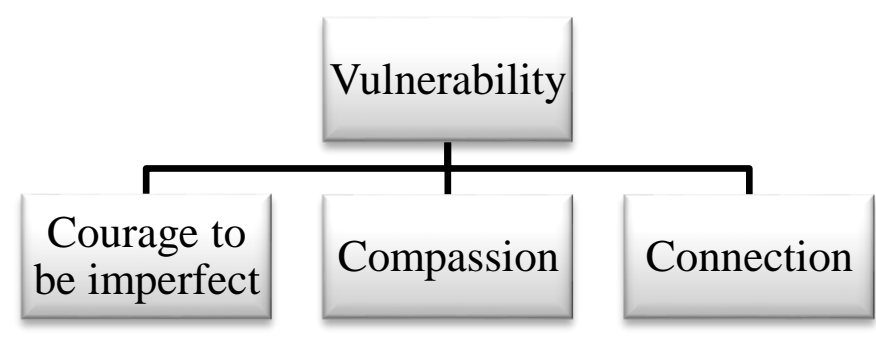

Figure 1: Factors to measure Vulnerability Source: Author

\section{RESEARCH METHODOLOGY}

This paper can be characterized as a formation through the present secondary data along with a brief insight into the workplace and employee perception. The books published by Dr. Brené Brown has a great contribution in the conceptualization of the basic idea behind the research. Various other published journals, papers and books have helped to create the perception towards the relevance of psychological safety, courage and vulnerability. Review was also done on the current relevance of these concepts and the perception of people for the implementation of these principles at workplace.

This Paper aims to provide an insight on the concepts and the factors relating to them which can create a potential for a quantitative research in the future and can therefore be referred as a conceptual paper. This report investigates three possible areas which can be incorporated within an organization to enhance the performance at workplace and enrich the process of growth.

\section{THEORETICAL FRAMEWORK}

\subsection{Psychological Safety and Courage}

Within an environment where we do not feel safe or comfortable enough to express our opinions, courageous decisions take a backseat and we often cover it up by things like what is the need to do it, why waste our time or there is no need of such decisions. The absence of psychological safety decreases our determination and the courage built in us. Psychological safety has been defined to be the shared vision showing the confidence that it is safe for inter-personal risk taking (Amy Edmondson, 1999).

In order to implement a culture reflecting psychological safety, the leaders must be courageous enough to speak out for the people of the organization. One must have the courage to 


\section{International Journal of Engineering Applied Sciences and Technology, 2020 Vol. 5, Issue 3, ISSN No. 2455-2143, Pages 562-567 \\ Published Online July 2020 in IJEAST (http://www.ijeast.com)}

tell people when they are wrong. In the absence of courage, it is difficult to create an environment of psychological safety since it would lead to a situation where you are seeing something wrong happening but are not speaking up due to the fear of the consequences that may follow even if you know you are right. The understanding of the relationship of these concepts is fruitful to foster growth of the organization.

The most significant reason behind the resistance to courageous decisions is the absence of psychological safety. Employees tend to keep their mouth shut and work according to what they are asked to in order to avoid being judged because of a bad idea. Some of the employees don't take such decisions in order to avoid the embarrassment that may follow or just because of the past experience where they took such a decision and it did not work out and they were later associated with that failure which makes them hesitant. (Bruno and Detert, 2017) The employer must understand the need of psychological safety for being courageous and act accordingly.

\subsection{Courage and Vulnerability}

Courage is associated with overcoming the fear and fear is the result of a perception of vulnerability. It can also be said that courageous decisions originate with the presence of vulnerabilities. Courage refers to the presence of fear in a certain amount and appropriate measures to overcome it (Aristotle-Nicomachean Ethics, 1980). A perception of vulnerability builds fear within us which when channelized allows us to evaluate the meaningfulness of the act and directs us towards a courageous decision.

Vulnerability can also be related to as the willingness to be seen despite uncertain outcomes and every act of courage lays its foundation through being vulnerable. If an employee exhibits the attribute of being vulnerable by admitting past mistakes, taking risks, embracing hard conversations etc., they are being vulnerable in front of others and such vulnerabilities fuel our paths towards courageous decisions and attitude at work. It allows one to accept them the way they are and to initiate creativity in the organization by expressing their opinions openly.

Courage is related to overcoming fear but where does this fear originate from, fear originates from a perception of vulnerability which is further build by the measurement done by a person regarding their personal resources and the threat that may overpower their resources. (Cooper R. Woodard, 2004) This shows the relationship between courage and vulnerability, in order to make this calculation accurate and to take better decisions it is necessary to recognize our vulnerabilities and build the courage to overcome those from being a negative aspect for us to channelize the risk towards a higher return.

As Dr. Brené Brown (2012) says the willingness of an individual to understand and engage with their vulnerabilities exhibits the degree of their courage and their clarity in approach. She also highlights that the level at which one tries to hide their vulnerabilities reflects the level of fear and the absence of connection with self.

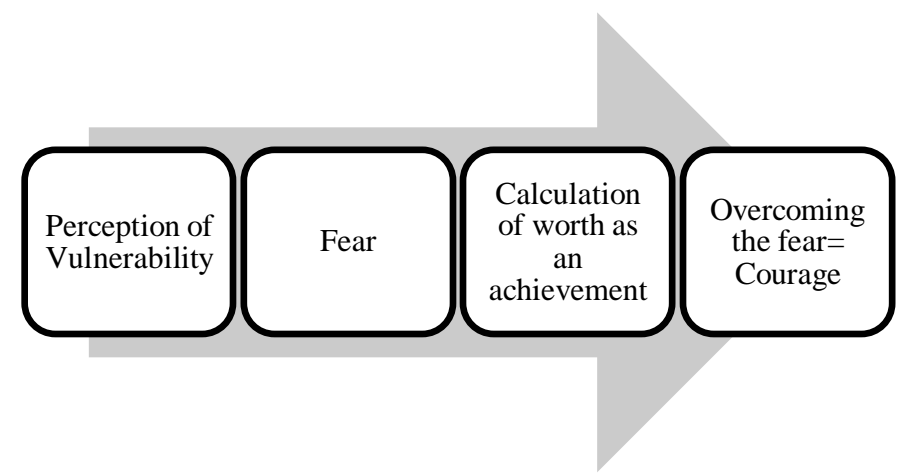

Figure 2: Relation between Vulnerability, Fear and Courage Source : Author

\subsection{Vulnerability and Psychological Safety}

Psychological safety tends to provide an environment which allows one to be vulnerable. A workplace where trust and safety exist the employees feel comfortable enough to accept their vulnerabilities. Such an environment helps to provide confidence to the employees to be who they are and not to try being someone else. It helps to exhibit a sense of authenticity. When people feel safe, then only they expose themselves to risk. Alternatively, an environment where leaders are willing to share their vulnerabilities, it tends to create an environment where the employees or all other members of the organization also adapt the feeling of safety in expressing their vulnerabilities or shortcomings and taking the risk. When they see others being open of their emotional state, they get motivated to open themselves towards others as well.

Volitional Vulnerability (volitional refers to the willingness of an individual) and Psychological Safety are shown to be positively related by Walter Brian Slipetz (2002). This is through the basis shown by Dr. Brené Brown (2018) and Edmondson (2002) where both reflect significant importance to a concept of image of a person. Vulnerability arises through a sense of not being enough and Psychological Safety is hampered due to the feeling of being seen to be someone who is ignorant, disruptive, negative and incompetent. This leads to a situation of "Vulnerability-avoidance" while we try to be someone else just so that others can think of us as someone better. Therefore, the presence of one of these factors in an organization creates space for the emergence of the other.

\subsection{Findings}

In order to understand the relevance and perceptions of people regarding the concepts of psychological safety, courage and vulnerability primary data was also used. A few leaders and employees were questioned regarding their perception of the application of these concepts through different concepts. Leaders were asked how they motivate themselves to take a risk, to which the leaders have stated what they tell themselves, which are: "Not attempting is bigger than failure, so it is better to try and fail which will certainly make you stronger and enrich your knowledge.", "At max what will happen, we will fail but we will learn from it and better ourselves.", "Think about the positive outcome and the 


\section{International Journal of Engineering Applied Sciences and Technology, 2020 Vol. 5, Issue 3, ISSN No. 2455-2143, Pages 562-567 \\ Published Online July 2020 in IJEAST (http://www.ijeast.com)}

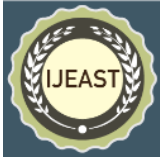

potential reward which might be bigger than the risk." This highlights their courage to try new things while understanding the uncertainty involved in the outcome.

Similarly, they were asked about how they help the employees to be courageous, some of the responses were: " Even spider man has to take a risk and jump. Take the risk. Learn and evolve.", "Express yourself without worrying about the outcome.", "Creating an environment which helps them to have faith in their abilities and environment." Another answer that shows the presence of an environment with the presence of vulnerability is, "I share my own weaknesses very often and talk them through their failure."

A question focussed on employees was about what motivates them to take a risk received responses like: learning opportunities, intuition based on past experiences, degree of risk, to overcome fears and accomplish goals, trust in the organization, personal satisfaction, importance of activity, to build confidence, to challenge themselves, love for work, for the company to grow, try something new, making an impact and various other factors. These aspects reflect the concept of psychological safety, courage and vulnerability.

The respondents were also asked about ways through which psychological safety is inculcated in their organization according to their perception, to which they highlighted some of the ways: By staying connected and having confidence in one another, by giving everyone the chance to speak their views and share any kind of issues they may be facing, two way and friendly channel of communication, trust on team members, by openness and respecting others, by discussion and many other ways. These methods are curated through the experience of the employees and can be used by other organizations since it provides and environment of psychological safety to the employees.

As highlighted by Judith V. Jordan (2008), a lot of times people relate courage as being a hero and doing things on our own without showing our vulnerabilities, but courage can be depicted by putting your actual self forward and acknowledging the contributions of others. Most people especially at workplace, try to be hide their weaknesses and defy from making real connections due to the threat of being inferior in front of one another. The denial of fear and vulnerability does not amount to being courageous decisions. The need to build connections and being authentic requires you to be vulnerable for once to create a connection and trust which helps you to build something new. Emotions are often related to being strong or weak. Emotions do not define your weakness but bottling those emotions in order to portray yourself as strong is a weakness. Emotions empower oneself to understand ourselves and the challenges faced by us. In today's competitive world, most of us would try to hide our weakness from others due to the undue pressure of being the hero which acts as a barrier to change and growth. This barrier can be broken through taking the first step of being vulnerable and acknowledging our fears which we can overcome through compassion, connection and the courage to be imperfect. Once a person gathers the courage to be vulnerable, not running behind the certainty the open the doors to curiosity, change and learning. If one portrays to know things that they actually don't, then they will never try to learn it as well which will hinder their growth.

\section{RESULTS AND DISCUSSION}

\subsection{Managerial Implications}

The understanding of these concepts can be passed to the employees through practice. If the managers of the organization start to put out their own vulnerabilities and weakness with their employees, they will also be motivated to do the same and realise that it is not necessary to know it all. They can then openly present their weaknesses and create them to a positive aspect. Managers must try not to call out people for just their wrong doings and rather focus on creating the wrong done as a learning experience for the employees and give them a chance to rectify their mistakes in order to make sure that one such act doesn't lead to the stopping of taking the risk to try out new things

\subsection{Conclusion}

It is true that a rational person doesn't take a risk without measuring its consequences, but it is also important to take risk at times to grow. No risk, no gain is something that is heard very often, but what are the things that help us take such a risk. The guiding force requires one to be courageous, it require one to be vulnerable enough to put one selves out there to the situation and itis important to have a culture in the organization where employees should feel secured while being judged.

Vulnerability in its true sense allows one to be compassionate towards self and others, have the courage to be imperfect and to build connections. It allows a person to remove their mask and be their real selves with all their weakness and help translate those weaknesses into strength. Once an environment which accepts and promotes vulnerability is created, the people in the organization tend to understand, trust and emotionally relate with each other. Further, Vulnerability is not a standalone concept, it walks hand in hand with psychological safety and courage. Psychological safety helps to create an environment where one is open to being vulnerable to a certain degree. In an environment that inculcates psychological safety, people feel free to express themselves without being judged which basically allows one to be vulnerable. Similarly, fear derives from a perception of vulnerability and the presence of such a fear gives one the opportunity to overcome these fears by being courageous. Vulnerability can be measured through three components as identified by Dr. Brené Brown, namely compassion, connection and courage to be imperfect. The presence of these aspects in an organization also helps to imbibe the atmosphere of psychological safety.

Psychological safety enables one to speak their minds, courage is the power to recognize and overcome our fears and vulnerability is the risk to exposure, uncertainty and putting our emotional selves out. These three concepts have a significant impact on the growth of both a person and an 


\section{International Journal of Engineering Applied Sciences and Technology, 2020 Vol. 5, Issue 3, ISSN No. 2455-2143, Pages 562-567 \\ Published Online July 2020 in IJEAST (http://www.ijeast.com)}

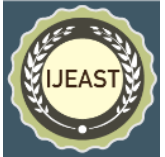

organization, since if a person builds the courage to recognize and voice out their weaknesses, they build a curiosity and opportunity to learn something new in order to overcome this weakness, which enables them to build their skills and abilities which would help them to be a better version of themselves. Similarly, when a person in an organizational setup puts forward their inabilities, it enables them to build connections with people having those skills in order to collectively achieve the organizational goals, this also helps a person to learn new things.

The presence of these concepts can assist in the development of an individual and to upgrade their skills and abilities. In context of a group, it could help in knowledge sharing and achieving bigger accomplishments together when the people open up with their share of weaknesses and collaborate to overcome those weaknesses. The organization as a whole can benefit from the understanding of these concepts as the employees will then want to stay in the organization and it would reduce the attrition rate and result in the growth of the organization and can also enhance the organization citizenship behaviour.

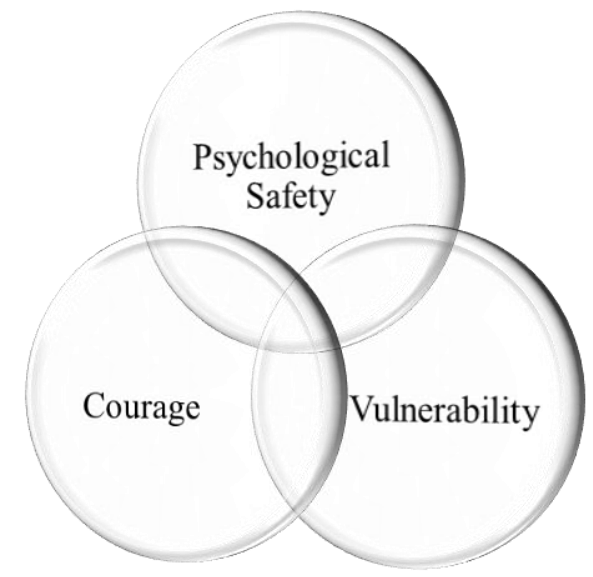

Figure 3 : Interconnectedness of Psychological Safety, Courage and Vulnerability.

Source : Author

Such an environment where one's vulnerabilities are not misused can be created with the proper and step by step implementation by the leaders. The leaders are the people who guide the path to their subordinates. If the leader tends to show their vulnerability, the people around them will be motivated to do the same and learn that failure and weakness is just a part and one must overcome them. The leaders must start building such an environment by first introducing psychological safety in the organization. When people are satisfied, motivated, aware and compassionate with themselves and the people around them they tend to take the first step towards expressing their vulnerability and being courageous in their actions. They will then be ready to take a risk and try out new things irrespective of the chances of failure, they would then be interested to learn new things. If one tries to hide their vulnerabilities, they would enter an exhausting process to hide them which is based on the belief that they are not strong enough to handle their challenges. Further, if the vulnerabilities are not recognised by the people then blame, defensiveness and shame will block the path of taking appropriate risks and employee performance.

These three factors can be seen to impact the presence of one another through the study of different researchers which reflects that when an organization goes ahead to implement one it would lead to the presence of the next as well. They are tied together through the perceptions formed by the members of the organization.

The aspect of vulnerability can be inculcated in the work environment through the building blocks of trust, transparency, inclusiveness within an organization, providing feedbacks, engaging the employees into healthy discussions and idea generation process. When different perceptions of people come together, it leads to the creation of something great. There should be no space for ego to come into work.

The environment of psychological safety can be created within the organization through various factors which have also been highlighted in the responses which is according to the perception of the people present in an organization. The leaders can allow the employees to collaborate and work together to build trust, create healthy discussions, value the opinions of others, respect each other irrespective of the role in the organization. They can further communicate that there is no space for shaming each other. The leaders are the ones who shape the organization and its practices, if the leader behaves in a way that makes the employees comfortable and not just judge them on the basis of their opinions and value it, the same will be followed by the employees. It can then be created as a part of the organizational culture.

Courage can be highlighted in the organization through the decisions taken by them. The aspect of courage at workplace can be inculcated through encouraging the employees to take risks, understanding new ideas and complementing them and create the environment where people are comfortable in putting their opinions.

The employees are one of the most essential aspects of the organization, without them there would be nothing left in the organization; therefore it is necessary to understand them and the aspects which can have a difference in their behaviour and the approach towards work.

\subsection{Limitations}

The limitation for this paper was that since these concepts are newly emerging in context to workplace and organization, there was limited literature and data available. There was a lack of prior research studies on some aspects of this topic. Most of the data included in the research are based on theoretical frameworks with less of a quantitative analysis to understand the functionality which can also be a future scope for the study on this topic.

Since the concepts are new in relation to the workplace the sample size was smaller due to a lesser understanding of these concepts by the people. The sampling was done through a 


\section{International Journal of Engineering Applied Sciences and Technology, 2020 Vol. 5, Issue 3, ISSN No. 2455-2143, Pages 562-567 \\ Published Online July 2020 in IJEAST (http://www.ijeast.com)}

technique of judgement sampling which could possibly lead to a bias in the responses.

\subsection{Future Scope of Study}

The present article not only discusses empirical research on psychological safety but also highlights gaps in the literature and offers guidance for future study. The scope of future research could extend to empirically weighing the pros and cons of this fresh paradigm to allow industry to take decisions on how to imbibe the concepts of psychological safety, courage, and vulnerability in the workplaces amongst the employees.

Further, the methods to measure psychological safety, courage and vulnerability can be put into practice to define an analytical framework for the relationship between these concepts along with the mediating factors.

\section{ACKNOWLEDGMENT}

We would like to thank all the researchers whose work has contributed to the formation of this paper and also to the people who have taken out time and cooperated with us by helping us gain an insight in their thoughts about these concepts. Further, we would like to extend our gratitude to International Journal of Engineering Applied Science and Technology (IJEAST) for giving us the opportunity to put forward our paper.

\section{REFERENCES}

1. Aristotle., Ross, W. D. \& Urmson J. O. (1980). Nicomachean Ethics. Oxford (Oxfordshire): Oxford University Press. DOI: https://doi.org/10.1093/actrade/9780199213610.book .1

2. Brown, B. (2010). Brené Brown: The power of vulnerability. TED. Retrieved from https://www.ted.com/talks/brene_brown_on_vulnera bility

3. Brown, C. B. (2012). The power of vulnerability. DOI: https://doi.org/10.1037/e517042011-001

4. Brown, B. (2015). Daring greatly: How the courage to be vulnerable transforms the way we live, love, parent, and lead. Penguin. DOI: 10.14324/111.444.ijsp.2017.17

5. Brown, B. (2018). Dare to lead: Brave work. Tough conversations. Whole hearts. New York: Random House. DOI: https://doi.org/10.14507/er.v27.2831

6. Detert, J. R., \& Bruno, E. A. (2017). Workplace courage: Review, synthesis, and future agenda for a complex construct. Academy of Management Annals, 11(2), 593-639. DOI: 10.5465/annals.2015.0155

7. Diener, R. B. (2013). The courage quotient: how science can make you braver. Seoul: Hanbitbiz, (Pg $5-24)$
8. Edmondson, A. (1999). Psychological safety and learning behaviour in work teams. Administrative science quarterly, 44(2), (pp. 350-383).

9. Edmondson, A. C. (2002). Managing the risk of learning: Psychological safety in work teams. Cambridge, MA: Division of Research, Harvard Business School (pp. 255-275)

10. Edmondson, A. C., Kramer, R. M., \& Cook, K. S. (2004). Psychological safety, trust, and learning in organizations: A group-level lens. Trust and distrust in organizations: Dilemmas and approaches, 12, (pp. 239-272).

11. Edmondson, A. C., \& Lei, Z. (2014). Psychological safety: The history, renaissance, and future of an interpersonal construct. Annu. Rev. Organ. Psychol. Organ. Behav., l(1), (pp. 23-43).

12. Jordan, J. V. (2008). Valuing vulnerability: New definitions of courage. Women \& Therapy, 31(2-4), (pp. 209-233).

13. Ming, C., Xiaoying, G., Huizhen, Z., \& Bin, R. (2015, April). A Review on Psychological Safety: Concepts, measurements, antecedents and Consequences variables. In 2015 International Conference on Social Science and Technology Education. Atlantis Press. DOI: https://dx.doi.org/10.2991/icsste-15.2015.118

14. Schein, Edgar H. (1985). Organizational Culture and Leadership. San Francisco: Jossey-Bass Publishers. (Pg. 305-350)

15. Schilpzand, P. (2008). Personal courage: A measure creation study. University of Florida. (Pg. 23-36)

16. Sinek, S. (2014). Leaders eat last: Why some teams pull together and others don't. Penguin. DOI: https://dx.doi.org/10.7899\%2FJCE-15-15

17. Slipetz, W. B. (2016). Volitional Vulnerability: From Qualitative to Quantitative (Doctoral dissertation). (Pg. 20-26)

18. Woodard, C. R. (2004). Hardiness and the Concept of Courage. Consulting Psychology Journal: Practice and Research, 56(3), $173 . \quad$ DOI: https://psycnet.apa.org/doi/10.1037/10659293.56.3.173 